\title{
Coalescence of Traditional Medicine Methods and System Biology Approaches Should Occur to Uncover the Molecular Basis of Remedies for Childhood Pneumonia
}

\author{
Ranadhir Chakraborty* \\ Department of Biotechnology, University of North Bengal, India
}

Submission: February 08, 2018; Published: February 22, 2018

*Corresponding author: Ranadhir Chakraborty, OMICS Laboratory, Department of Biotechnology, University of North Bengal, West Bengal, India, Email: rcnbusiliguri@gmail.com

Abstract

The treatment decisions in children with pneumonia depend on the age, clinical status, and probable etiology of the infectious agent. There are several age-old practices for healing childhood pneumonia. Homeopathic remedies for pneumonia are also known. Several herbs and plant parts have usages in treating pneumonia. From the treasure trove of several dispersed-unsynchronized scientific studies and ethno-knowledge, it emerges that synergistic formulation based on plant and animal ingredients are highly effective in the treatment and prophylaxis of pneumonia among children. These practices have undergone several human trials as it bear centuries-old tradition. Hence, multi-component therapy may provide revived medication(s) to save millions of children dying every year due to pneumonia with the rider that it has to be validated and scientifically scrutinized for multiple perturbations of biological networks, in addition to multiple targets with system biology tools, now available, to establish the basis of multi-component therapy.

\section{General Perception About Pneumonia}

Pneumonia is a lung infection that can be caused by different types of microorganisms including bacteria, viruses, and fungi. Symptoms of pneumonia include cough with sputum production, fever, and sharp chest pain on inspiration (breathing in). Bacterial and fungal (but not viral) pneumonia can be treated with antibiotics. Bacteria causing pneumonia can be identified by sputum culture. Viral pneumonias do not typically respond to antibiotic treatment. These pneumonias usually resolve over time with the body's immune system fighting off the infection.

\section{Symptoms of Childhood Pneumonia}

The symptoms vary as per age of the children

i. Coughing and fever may not often observed in pneumonia affected newborns but symptoms like rapid breathing with flaring nostrils, disinterest in feeding, and blue tint to the skin.

ii. Infants ( $>01$ month old) on contracting pneumonia may manifest a fever, even though there could be no fever in case of viral pneumonia. Wheezing sound may be heard.

iii. Toddlers ( $\leq 24$ month old) affected with pneumonia often suffer from stomach troubles along with vomiting and tenderness in the abdomen. The common symptom is coughing.

iv. Older children ( $>24$ months) contracting pneumonia, likely to have a strong cough, often have a past record of colds and flu.

\section{Causes of Childhood Pneumonia}

When vaccines did not exist, investigating the cause of childhood pneumonia was of great concern because specific therapeutic measures were taken only after conducting both etiological diagnosis and serotyping. Streptococcus pneumonia (pneumococcus) and Haemophilus influenzae were found to be the most predominant causal organisms for pneumonia. Staphylococcus aureus and Klebsiella pneumoniae were also detected in case of some severities [1].

\section{Mainstream Treatments For Childhood Pneumonia}

Age, clinical status, and probable etiology of the infectious agent dictate the treatment decisions in children with pneumonia. In order to determine the causal organism, blood and swab tests are done. In an orthodox clinical set up, antibiotics are administered on the basis of the most likely organism, considering 
the age of the child, the history of exposure, the possibility of resistance, and other relevant clinical records. In case of severe infection, antibiotics and fluids are given intravenously and in dire state oxygen are provided via mask. Pneumonias caused by fungi are treated with specific antifungal drugs.

\section{Some Unorthodox Treatments of Childhood Pneumonia}

i. A study carried out on forty Philippine children, age ranging from 03-60months, all diagnosed with communityacquired pneumonia, being treated with coconut oil have shown much speedier and complete recovery. All the forty children were treated with ampicillin; of them twenty received coconut oil dosages as per body weight. Children resumed normal respiratory rate and blood oxygenation in $<33 \mathrm{~h}$ post-coconut oil treatment. However, such results are not definitive as sample number was small and were devoid of considering other variables. The current hypothesis in explaining the healing principle of coconut oil is in favor of lauric acid which may act as an immune-stimulant compound and thus enhance the efficacy of the antibiotic.

ii. An age-old remedy for chest colds and pneumonia has been the mustard plasters. For treating childhood pneumonia, mustard plaster is never applied to skin directly. About 50g of mustard seed (be it yellow or black) is ground and mixed with $60 \mathrm{ml}$ of warm water to make a paste. The warm paste sandwiched between two pieces of clean cloth is held over child's chest until the child whines of the burning sensation. By the time plaster is removed, the essential oils present in the plaster are thought to have done the job of healing.

iii. Homeopathic remedies for pneumonia include Aconite, Ferrum phosphoricum, Iodine, Veratrum viride, and Bryonia. Aconite is used in relieving pulmonary congestions. It is the remedy of remedies in the first stage of pneumonia, because it corresponds more closely to the symptoms usually found in that stage. Ferrum phosphoricum, like aconite, is a remedy for the first stage before exudation takes place and also in cases where violent congestions of the lungs take place, whether appearing at the onset of the diseases or during its course, which would show that the inflammatory action was extending thus corresponding to secondary pneumonias. Iodine is used for remediation of the first and second stage of pneumonia. In case of violent congestions of the chest preceding pneumonia, Veratrum viride may be the remedy. The use of Veratrum viride is more in the beginning of the disease, and especially where there is great arterial excitement, dyspnoea, chest congestions and stomach symptoms of nausea and vomiting. Bryonia furnishes a better pathological picture of the disease than any other, and it comes in after Aconite, Ferrum phosphoricum and Veratrum viride. iv. Several herbs and plant parts have usages in treating pneumonia; for example the Native American tribes use Pleurisy root for remediation of lung infection; although there is no evidence from clinical studies to support its use. Traditional Chinese medicine, combined treatment of acupuncture and herbs like xie bai san (Mulberry and Lycium formula) and banxia houpto tang (Pinellia and Magnolia formula), applied on $>50$ children suffering from childhood pneumonia have yielded complete cure in $80 \%$ of the treated children [2]. Bromelain (an enzyme extract derived from the juice and stems of pineapples having a history of use as folk medicine) when administered orally to 124 hospitalized patients, suffering from several lung diseases including pneumonia, was found efficacious in reducing the volume and pus-like quality of the sputum [3]. Several herbal preparations made of Berberis vulgaris (barberry root bark), B. aquifolium (Oregon grape root) and Hydrastis canadensis (goldenseal) contain a potential antibacterial compound, berberine, to fight infections [4]. Respiratory infections in children were shown to be prevented by a Lactobacillus probiotic preparation [5]. From the treasure trove of several dispersed-unsynchronized scientific studies and ethnoknowledge, it emerges that synergistic formulation based on plant and animal ingredients are highly effective in the treatment and prophylaxis of pneumonia among children. Synergistic traditional formulation of herbal ingredient of Leucas aspera and animal constituent of Periplanata americana useful for the treatment and prophylaxis of pneumonia and pneumonites has been practiced in Pratapgarh district of Uttar Pradesh, India. Practitioners of Indian Ayurvedic medicine and traditional Chinese medicine did not only discover active plants, but they also developed a holistic approach in their medical systems. A recent paper from India, re-investigated the said formulation and evaluated the curative and prophylactic activity on pneumonia-affected children $<1$ to 6 years of age [6].

These practices have undergone several human trials as it bear centuries-old tradition and therefore such multicomponent therapy may provide revived medication(s) to save millions of children dying every year due to pneumonia with the rider that it has to be validated and scientifically scrutinized for multiple perturbations of biological networks, in addition to multiple targets with system biology tools, now available, to establish the basis of multi-component therapy. Cellular activity in health and disease, that was understood as relatively disconnected linear pathways, is now recognized as a complex interdependent web of regulatory, structural, and metabolic signaling pathways among cells. A more holistic approach using systems biology seems much more suited to proof efficacy and to obtain information that might lead to understanding the mode of action. Experiments should be designed to support the idea that chemical matrices are not only the evolutionarily established norm for shifting physiological processes, but may be superior 
for interfacing with the robust and complex cellular systems of life, including humans.

\section{References}

1. Shann F (1986) Etiology of severe pneumonia in children in developing countries. Pediatr Infect Dis 5(2): 247-252.

2. Bao J (1998) TCM differential treatment of child hood persisting pneumonia--a report of 52 cases. J Tradit Chin Med 18(3): 174-177.

3. Schafer AI, Adelman B (1985) Plasmin inhibition of platelet function and of arachidonic acid metabolism. J Clin Invest 75(2): 456-461.
4. Kaneda Y, Torii M, Tanaka T, Aikawa M (1991) In vitro effects of berberine sulphate on the growth and structure of Entamoeba histolytica, Giardia lamblia and Trichomonas vaginalis. Ann Trop Med Parasitol 85(4): 417-425.

5. Wanke CA (2001) Do probiotics prevent childhood illnesses. The BM] 322(7298): 1318-1319.

6. Pandey HP, Khan N, Chauhan SK (2008) A traditional panacea for pneumonia and pneumonites. Indian Journal of Traditional Knowledge 7(4): 673-675.
(C) This work is licensed under Creative

Your next submission with Juniper Publishers
will reach you the below assets
- Quality Editorial service
- Swift Peer Review
- Reprints availability
- E-prints Service
- Manuscript Podcast for convenient understanding
- Global attainment for your research
- Manuscript accessibility in different formats
( Pdf, E-pub, Full Text, Audio)
- Unceasing customer service
$\quad$ Track the below URL for one-step submission
https://juniperpublishers.com/online-submission.php

